\title{
Kajian Dinding Penahan Tanah \\ Pada Tebing Sungai Untuk Pengendalian Banjir
}

\author{
Ishak $^{1)}$, Ruwiyo ${ }^{2)}$ \\ 1) Prodi Teknik Sipil UMSB, Jorong Limo Kampuang Sei. Puar Kab. Agam \\ email : ishakumsb@gmail.com \\ 2) Dinas Pekerjaan Umum Propinsi Jambi, Perumahan Dahlia Indah Kota Jambi \\ email : ruwiyopu@yahoo.co.id
}

\section{ABSTRACT}

The retaining wall is one of the most important construction works in a project work and can affect the subsequent work and the end result of the project, the planning, calculation and design must be precise and accurate. Good analysis is also needed because there are many factors that affect in it, such as land properties, groundwater levels, and so forth. In order to produce the ideal retaining wall construction, the wall stability analysis needs to be reviewed for the safety factor of sliding and overturning must be adequate and the soil pressure occurring on the foundation soil should not exceed the capacity of the allowable carrying capacity. Planning of this retaining wall structure is planned to be safe against shifting, overthrowing, and collapsing soil carrying capacity. The analysis result obtained stability factor to shear 2,067, stability to bolster 3,258 and collapse of soil capacity of 3,033.

Keywords: retaining wall, sliding, overturning.

\section{INTISARI}

Dinding penahan tanah merupakan salah satu pekerjaan konstruksi yang penting dalam suatu pekerjaan proyek dan dapat mempengaruhi pekerjaan selanjutnya serta hasil akhir dari proyek tersebut maka perencanaan, perhitungan dan perancangan harus dilakukan dengan tepat dan akurat. Analisis yang baik juga diperlukan karena ada banyak faktor yang mempengaruhi di dalamnya, seperti properti tanah, muka air tanah, dan lain sebagainya. Untuk menghasilkan konstruksi dinding penahan tanah yang ideal, maka analisis stabilitas dinding perlu ditinjau faktor aman terhadap geser (sliding) dan guling (overtuning) harus mencukupidan tekanan tanah yang terjadi pada tanah dasar pondasi tidak boleh melebihi kapasitas daya dukung yang diizinkan. Perencanaan struktur dinding penahan tanah ini direncanakan aman terhadap pergeseran, penggulingan, dan keruntuhan kapasitas daya dukung tanah. Hasil analisis didapat faktor stabilitas terhadap geser 2,067, stabilitas terhadap guling 3,258 dan keruntuhan kapasitas daya dukung 3,033.

\section{PENDAHULUAN}

Dinding penahan tanah adalah sebuah struktur yang didesain dan dibangun untuk menahan tekanan lateral (horizontal) tanah ketika terdapat perubahan dalam elevasi tanah yang melampaui sudut at-rest dalam tanah. Faktor penting dalam mendesain dan membangun dinding penahan tanah adalah mengusahakan agar dinding penahan tanah tidak bergerak ataupun tanahnya longsor akibat gaya gravitasi. Tekanan tanah lateral di belakang dinding penahan tanah bergantung kepada sudut geser dalam tanah $(\phi)$ dan kohesi (c). Tekanan lateral meningkat dari atas sampai ke bagian paling bawah pada dinding penahan tanah.

Dinding penahan tanah merupakan salah satu pekerjaan konstruksi yang penting dalam suatu pekerjaan proyek dan dapat mempengaruhi pekerjaan selanjutnya serta hasil akhir dari proyek tersebut maka perencanaan, perhitungan dan perancangan harus dilakukan dengan tepat dan akurat. Analisis yang baik juga diperlukan karena ada banyak faktor yang 
mempengaruhi di dalamnya, seperti properti tanah, muka air tanah, dan lain sebagainya.

Menurut Gunawan T dan Margaret S (2006) dalam merencanakan dinding penahan tanah (retaining wall), Sheet Pile, atau struktur penahan tanah lainnya, adalah sangat penting untuk menghitung besarnya tekanan tanah lateral akibat tanah yang berada dibelakang struktur tersebut agar mampu menahan tekanan tanah secara aman dan juga sebagai parameter perencanaan dalam sejumlah persoalan teknik.

Tekanan lateral dikelompokkan kedalam 3 keadaan, yaitu :

1.Tekanan tanah aktif

2.Tekanan tanah pasif

3.Tekanan tanah diam

Tekanan lateral dalam keadaan aktif terjadi apabila tanah bergerak menekan misalkan pada dinding penahan tanah sehingga dinding penahan tanah bergerak menjauhi tanah belakangnya.

Tekanan lateral dalam keadaan pasif terjadi pada tanah yang berada didepan dinding penahan tanah karena dinding menekan tanah tersebut.

Tekanan lateral dalam keadaan diam adalah tekanan lateral yang ada dalam tanah yang tidak disebabkan oleh adanya dorongan lateral.

\section{Tekanan Tanah Akibat Beban}

Beban yang bekerja baik pada sisi tanah ataupun pada sisi galian akan menyebabkan tambahan tekanan lateral pada dinding. Beban yang bekerja dapat berupa : beban merata, beban titik, beban garis dan beban jalur.

\section{A. Beban Terbagi Rata}

Menurut Hary Christady Hardiyatmo (2010) kadang-kadang tanah urug dibelakang dinding penahan tanah dipengaruhi oleh beban terbagi rata. Dengan menganggap beban terbagi rata q sebagai beban tanah setebal hs dengan berat volume $(\gamma)$ tertentu, maka tinggi lapisan tanah hs $=\mathrm{q} / \gamma$ (Gambar 1). Tekanan tanah lateral pada kedalaman hs dari tinggi tanah anggapan (atau dipermukaan tanah urug) akan sebesar :

$\mathrm{Pa}=$ hs $\quad \gamma \quad \gamma \quad \mathrm{Ka}$
Jadi akibat adanya beban terbagi rata ini, tambahan tekanan tanah aktif total pada dinding penahan tanah setinggi $\mathrm{H}$ dapat dinyatakan oleh persamaan :

$\mathrm{Pa}^{\prime}=\mathrm{q} . \mathrm{Ka} . \mathrm{H}$

….... (2)

dengan,

$\mathrm{Pa}^{\prime}=$ tambahan tekanan tanah aktif total akibat beban terbagi rata

$\mathrm{q}=$ beban terbagi rata

$\mathrm{H} \quad=$ tinggi dinding penahan

$\mathrm{Ka} \quad=$ koefisien tekanan tanah aktif

Diagram tekanan aktif akibat beban terbagi rata ini akan berupa segi empat dengan tinggi $\mathrm{H}$ dan lebar sisi a . Ka

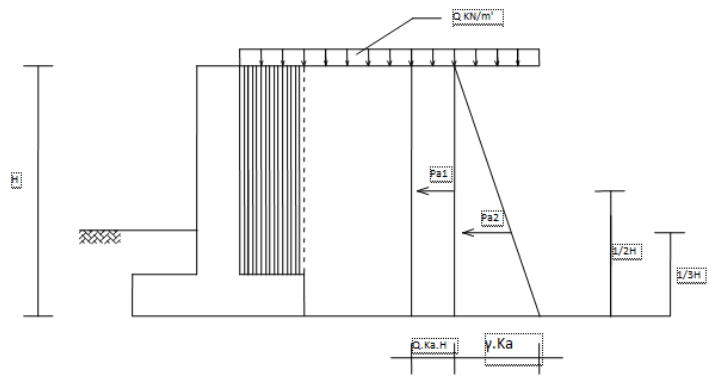

Gambar 1 : Diagram Tekanan Pengaruh Muatan Merata

Sumber : Bambang Surendro, 2014

B. Beban Titik

Menurut Bambang Surendro (2014) apabila beban titik (P) berada pada jarak H1 dari muka dinding vertikal, maka beban ini akan memberikan tekanan pada dinding sebesar dengan diagram tekanan berbentuk segitiga terbalik. Batas diagram segitiga tersebut, yaitu batas atas adalah titik yang ditentukan dengan menarik garis dari beban $\mathrm{P}$ dengan sudut $\phi$ (titik M), sedangkan batas bawah adalah titik yang ditentukan dengan menarik garis dari beban $\mathrm{P}$ dengan sudut $45^{\circ}+\Phi / 2$ (titik $\left.N\right)$, lihat Gambar 2 .

\section{(1)}




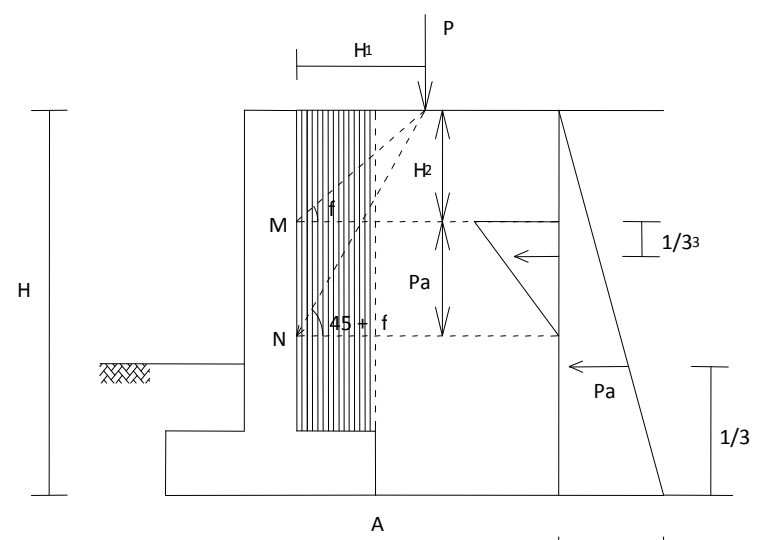

Gambar 2 : Diagram Tekanan Pengarkưh Titik

Sumber : Bambang Surendro, 2014

\section{Tekanan Pengaruh Air Tanah}

Stabilitas suatu dinding penahan tanah tidak hanya bergantung pada tekanan tanah yang bekerja saja akan tetapi juga pada tekanan air tanah yang bekerja pada dinding tersebut. Dengan adanya air tanah, maka berat isi tanah harus menggunakan berat isi tanah terendam $(\gamma$ submerged $-\gamma$ buoyancy) yang biasa diberi notasi :

$$
\begin{aligned}
& \gamma^{1}=\gamma \mathrm{b}-\gamma \mathrm{sub} \\
& \gamma^{1}=\gamma-\gamma \mathrm{H} \\
& \text { dimana: } \gamma=\gamma \mathrm{t}= \\
& \gamma^{1}=\gamma \mathrm{b}=\gamma \mathrm{sub} \quad=
\end{aligned}
$$

berat isi tanah terendam (ton $/ \mathrm{m}^{3}$ )

$$
\gamma \mathrm{w} \underset{\left(\text { ton } / \mathrm{m}^{3}\right)}{ }=\text { berat isi air }
$$

air tawar $\quad\left(\right.$ ton $\left./ \mathrm{m}^{3}\right)$

untuk air laut $\gamma \mathrm{w}=1 \quad=\quad$ untuk

Akibat adanya air tanah ini tekanan tanah aktif dan tekanan tanah pasif menjadi berkurang nilainya.

\section{METODE PENELITIAN \\ Pengumpulan Data}

Kebutuhan data merupakan masukan yang sangat penting untuk mengidentifikasikan dan merumuskan permasalahan penelitian yang ada secara sistimatis, sehingga tujuan dari penelitian menjadi lebih mudah dilakukan.
Untuk menunjang penelitian ini sangat diperlukan data-data pendukung, data pendukung yang digunakan dalam penulisan penelitan ini berupa data sekunder yaitu data yang didapat dari Satuan Kerja Non Vertikal Tertentu (SNVT) Pelaksana Jaringan Sumber Daya Air Sumatera Provinsi Jambi, Balai Wilayah Sungai Sumatera VI berupa data hasil sondir tanah.

\section{Langkah-Langkah Penelitian}

Langkah-langkah penelitian ini dapat diuraikan sebagai berikut :

1. Membuat tinjauan kepustakaan yang mendukung dalam penelitian.

2. Mengumpulkan data-data yang diperlukan dalam penelitian berupa data sekunder.

3. Menganalisa dan mengolah data yang telah didapat untuk penelitian.

4. Menentukan tipe dan ukuran dinding.

5. Perhitungan tekanan tanah.

6. Perhitungan stabilitas.

7. Membuat kesimpulan dan saran hasil penelitian 


\section{Bagan alir Penelitian}

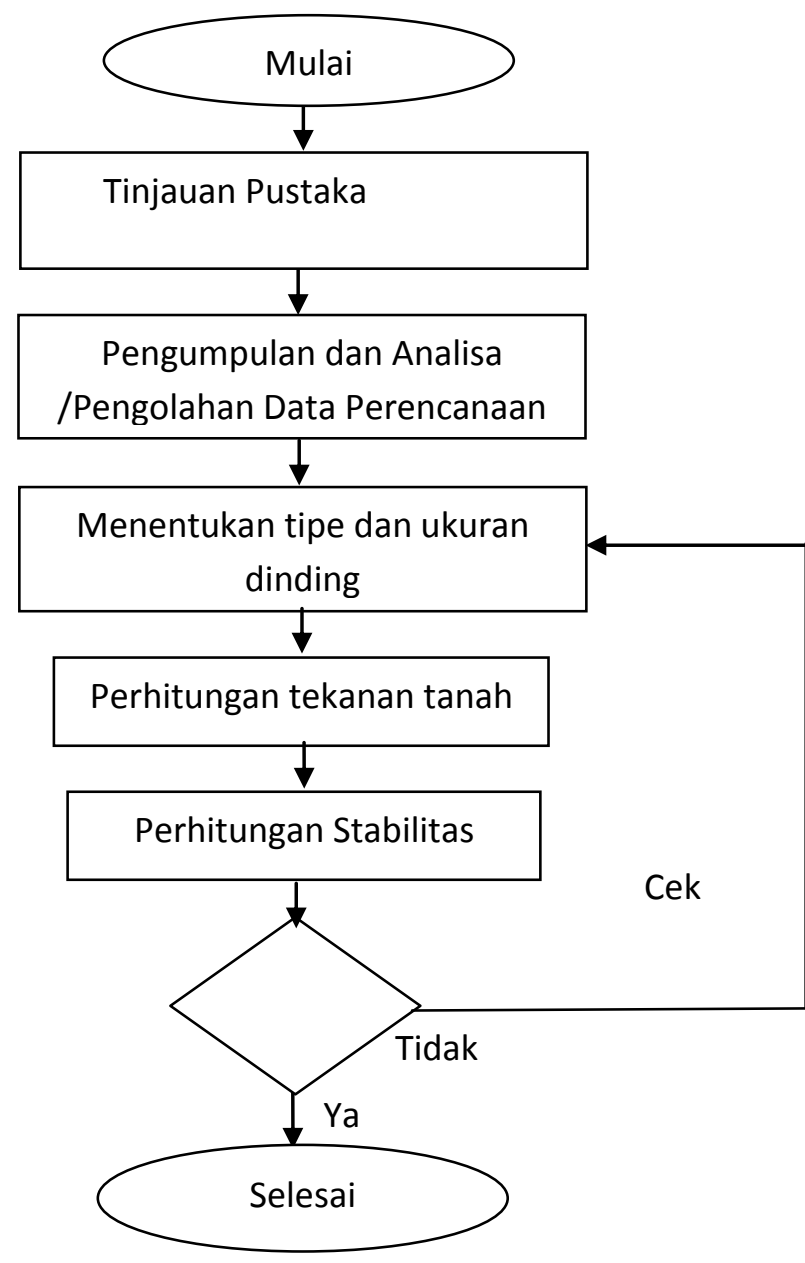

Gambar 3 : Bagan Alir Penulisan

Sumber : Hasil Analisa, 2017

\section{HASIL DAN PEMBAHASAN \\ Penentuan Tipe dan Ukuran Dinding}

Dinding penahan adalah suatu struktur bangunan untuk menahan tanah agar tidak longsor akibat beban yang bekerja atau mencegah keruntuhan tanah yang curam biasa kemantapannya tidak dapat dijamin oleh lereng tanah itu sendiri dan dipengaruhi oleh kondisi gambaran topografi tempat itu. Dinding penahan tanah yang direncanakan dengan tipe dinding penahan gravitasi. Gaya-gaya yang bekerja pada dinding penahan tanah antara lain mencakup (Hardiyatmo, 2011) : a. Berat sendiri dinding penahan tanah (W)

b. Gaya tekanan tanah aktif $(\mathrm{Pa})$

c. Gaya tekanan tanah pasif (Pp)

d. Tekanan air didalam tanah $(\mathrm{Pw})$

e. Reaksi tanah dasar (R)

Untuk menghasilkan konstruksi dinding penahan tanah yang ideal, maka analisis stabilitas dinding perlu ditinjau terhadap hal-hal sebagai berikut :

a. Faktor aman terhadap geser (sliding) dan guling (overturning) harus mencukupi.

b. Tekanan tanah yang terjadi pada tanah dasar pondasi tidak boleh melebihi kapasitas daya dukung yang diizinkan. Ukuran dinding penahan tanah adalah :

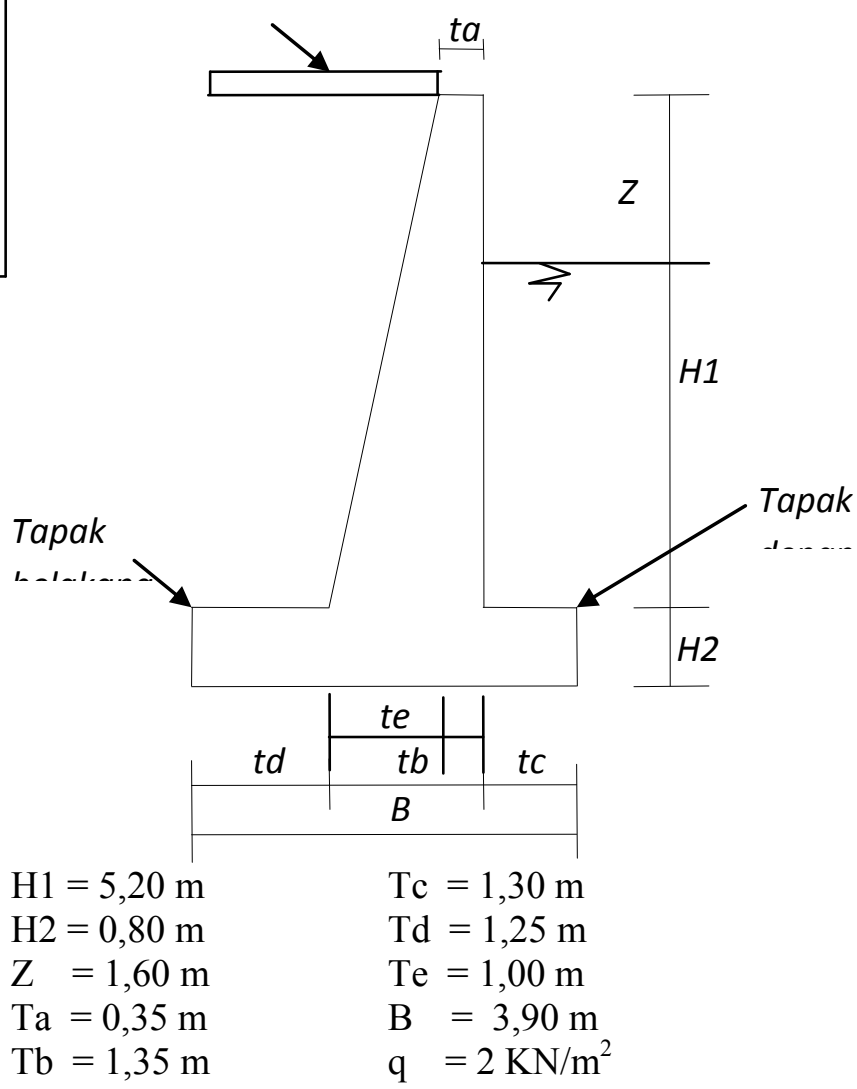

\section{Perhitungan Tekanan Tanah}

a. Perhitungan beban dan gaya yang bekerja pada dinding penahan 


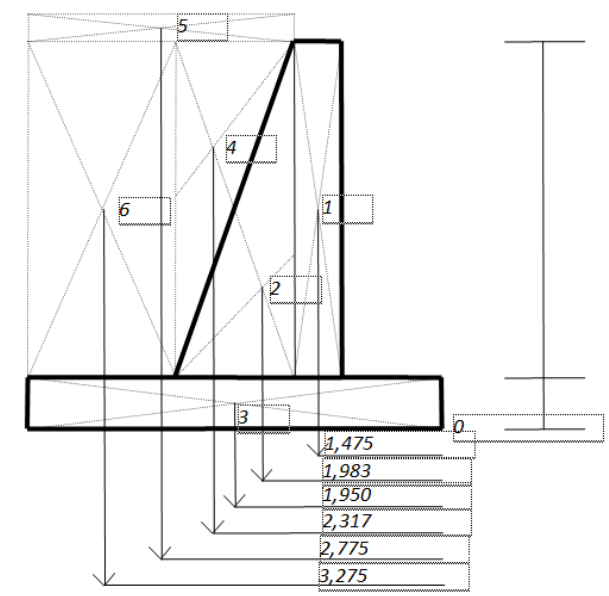

Berat dinding penahan tanah dan beton diatasnya

Bidang 1

$\mathrm{W} 1=\mathrm{p} .1 \cdot \gamma$

$=5,2 \cdot 0,35 \cdot 24$

$=43,68 \mathrm{KN} / \mathrm{m}$

Bidang 2

$\mathrm{W} 2=1 / 2 \cdot \mathrm{a} \cdot \mathrm{t} \cdot \gamma$

$=1 / 2 \cdot 1 \cdot 5,2 \cdot 24$

$=62,40 \mathrm{KN} / \mathrm{m}$

Bidang 3

$\mathrm{W} 3=\mathrm{p} .1 . \gamma$

$=3,9.0,8.24$

$=74,88 \mathrm{KN} / \mathrm{m}$

Bidang 4

$$
\begin{aligned}
\mathrm{W} 4 & =1 / 2 \cdot \mathrm{a} \cdot \mathrm{t} \cdot \gamma \\
& =1 / 2 \cdot 1 \cdot 5,2 \cdot 16,4 \\
& =42,64 \mathrm{KN} / \mathrm{m}
\end{aligned}
$$

Bidang 5

$\mathrm{W} 5=\mathrm{q} .1$

$=2.2,25$

$=4,50 \mathrm{KN} / \mathrm{m}$

Bidang 6

$$
\begin{aligned}
\mathrm{W} 6 & =\mathrm{p} \cdot 1 \cdot \gamma \\
& =5,2 \cdot 1,25 \cdot 16,4 \\
& =106,60 \mathrm{KN} / \mathrm{m}
\end{aligned}
$$

Jarak beban terhadap ujung dinding penahan (titik 0)

1. X1 $=(1 / 2 \cdot 0,35)+1,30=$

$1,475 \mathrm{~m}$

2. $\mathrm{X} 2=(1 / 3.1)+0,35+1,30=1,983 \mathrm{~m}$
3. $\mathrm{X} 3=(1 / 2.3,9)$

$1,950 \mathrm{~m}$

4. $\mathrm{X} 4=(2 / 3.1)+0,35+1,30=2,317 \mathrm{~m}$

$5 . \mathrm{X} 5=(1 / 2 \cdot 2,25)+0,35+1,30=$

$2,775 \mathrm{~m}$

6. $\mathrm{X} 6=(1 / 2.1,25)+1+0,35+1,30=3,275 \mathrm{~m}$

Momen terhadap ujung dinding penahan (titik

0)

$$
\begin{aligned}
\mathrm{M} 1 & =\mathrm{W} 1 \cdot \mathrm{X} 1 \\
& =43,68 \cdot 1,475 \\
& =64,428 \mathrm{KN} \\
\mathrm{M} 2 & =\mathrm{W} 2 \cdot \mathrm{X} 2 \\
& =62,40 \cdot 1,983 \\
& =123,760 \mathrm{KN} \\
\mathrm{M} 3 & =\mathrm{W} 3 \cdot \mathrm{X} 3 \\
& =74,88 \cdot 1,950 \\
& =146,016 \mathrm{KN} \\
\mathrm{M} 4 & =\mathrm{W} 4 \cdot \mathrm{X} 4 \\
& =42,64 \cdot 2,317 \\
& =98,783 \mathrm{KN} \\
\mathrm{M} 5 & =\mathrm{W} 5 \cdot \mathrm{X} 5 \\
& =4,50 \cdot 2,775 \\
& =12,488 \mathrm{KN} \\
\mathrm{M} 6 & =\mathrm{W} 6 \cdot \mathrm{X} 6 \\
& =106,60 \cdot 3,275 \\
& =349,115 \mathrm{KN}
\end{aligned}
$$

Tabel 1. Gaya vertikal dan momen tahanan yang bekerja

\begin{tabular}{|c|l|c|c|c|}
\hline $\begin{array}{c}\text { Seg } \\
\text { men }\end{array}$ & Luas $\left(\mathrm{m}^{2}\right)$ & $\begin{array}{c}\text { Berat/Sat } \\
\text { uan } \\
\text { Panjang } \\
(\mathrm{KN} / \mathrm{m})\end{array}$ & $\begin{array}{c}\text { Leng } \\
\text { an } \\
\text { Mom } \\
\text { en } \\
(\mathrm{m})\end{array}$ & $\begin{array}{c}\text { Momen } \\
\text { Terhadap } \\
\text { Titik } \\
0(\mathrm{KNm})\end{array}$ \\
\hline $\mathrm{a}$ & $\mathrm{b}$ & $\mathrm{C}=\mathrm{b} \mathrm{x} \gamma$ & $\mathrm{d}$ & $\mathrm{e}=\mathrm{c} \mathrm{x} \mathrm{d}$ \\
\hline 1 & $\begin{array}{l}\mathrm{X} 1=0,35 \mathrm{x} \\
5,20 \\
=1,82\end{array}$ & 43,68 & $\begin{array}{c}1,47 \\
5\end{array}$ & 64,428 \\
\hline 2 & $\begin{array}{l}\mathrm{X} 2=(1 / 2 \times 1 \\
\mathrm{x} 5,20) \\
=2,60\end{array}$ & 62,40 & 1,98 & 123,760 \\
\hline 3 & $\begin{array}{l}\mathrm{X} 3=3,9 \times \\
0,80 \\
=3,12\end{array}$ & 74,88 & 1,95 & 146,016 \\
\hline 4 & $\begin{array}{l}\mathrm{X} 4=(1 / 2 \times 1 \\
\mathrm{x} 5,20) \\
=2,60\end{array}$ & 42,64 & 2,31 & 98,783 \\
\hline
\end{tabular}




\begin{tabular}{|c|l|c|c|c|}
\hline 5 & $\begin{array}{l}\mathrm{X} 5=2,25 \times 1 \\
=2,25\end{array}$ & 4,50 & $\begin{array}{c}2,77 \\
5\end{array}$ & 12,488 \\
\hline 6 & $\begin{array}{l}\mathrm{X} 6=1,25 \times \\
5,20 \\
=6,50\end{array}$ & 106,60 & $\begin{array}{c}3,27 \\
5\end{array}$ & 349,115 \\
\hline \multicolumn{2}{|r}{$\Sigma \mathrm{V}$} & 334,700 & $\Sigma \mathrm{MR}$ & 794,589 \\
\hline
\end{tabular}

Sumber : Hasil Perhitungan, 2017

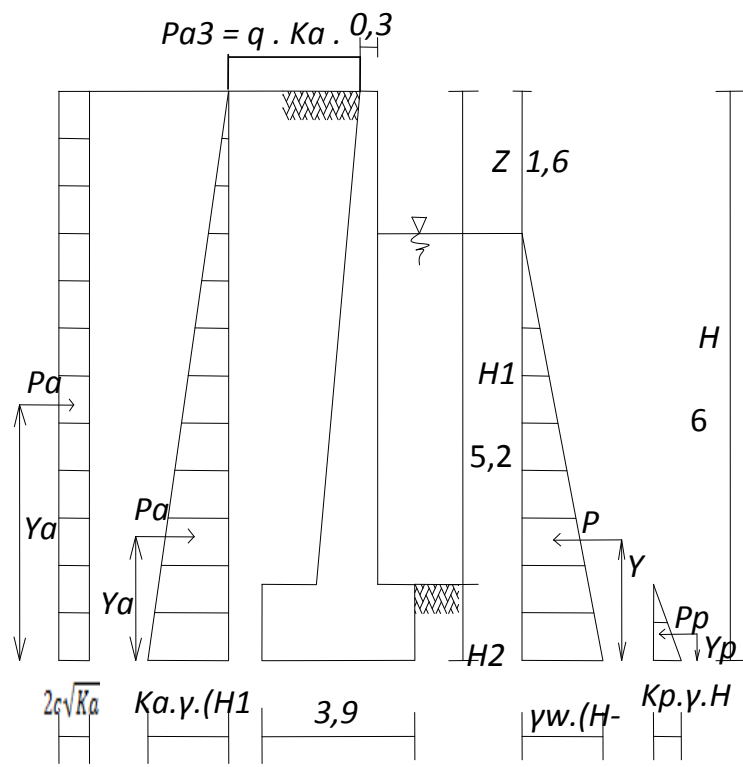

Perhitungan tekanan tanah

Tekanan tanah aktif metode Rankine

$$
\begin{aligned}
k a & =\operatorname{Tan}^{2}\left(45-\frac{\emptyset}{2}\right) \\
& =\operatorname{Tan}^{2}\left(45^{\circ}-\frac{31,5}{2}\right) \\
& =0,310 \\
\mathrm{~Pa} 1 & =1 / 2 \cdot \mathrm{Ka} \cdot \gamma \cdot(\mathrm{H} 1+\mathrm{H} 2)^{2} \\
& =1 / 2 \cdot 0,310 \cdot 16,4 \cdot(5,20+ \\
0,80)^{2} & \\
& =91,542 \mathrm{KN} / \mathrm{m} \\
\mathrm{Pa} 2 & =2 \cdot \mathrm{c} \cdot \sqrt{\mathrm{Ka}}(\mathrm{H} 1+\mathrm{H} 2) \\
& =2 \cdot 4 \cdot(5,20+0,80) \\
& =26,725^{\sqrt{0 N} 310} \\
\mathrm{~Pa} 3 & =\mathrm{q} \cdot \mathrm{Ka} \cdot(\mathrm{H} 1+\mathrm{H} 2)
\end{aligned}
$$

$$
\begin{aligned}
& =2 \cdot 0,310 \cdot(5,20+0,80) \\
& =3,720 \mathrm{KN} / \mathrm{m} \\
\Sigma \mathrm{Pa} & =\mathrm{Pa} 1+\mathrm{Pa} 2+\mathrm{Pa} 3 \\
& =91,542+26,725+3,720 \\
& =121,957 \mathrm{KN} / \mathrm{m}
\end{aligned}
$$

Tekanan tanah pasif metode Rankine

$$
\begin{aligned}
k p & =\operatorname{Tan}^{2}\left(45+\frac{\emptyset}{2}\right) \\
& =\operatorname{Tan}^{2}\left(45^{\circ}+\frac{31,5}{2}\right) \\
& =3,190 \\
\mathrm{Pp} & =1 / 2 \cdot \mathrm{Kp} \cdot \gamma \cdot \mathrm{H} 2^{2} \\
& =1 / 2 \cdot 3,190 \cdot 16,4 \cdot 0,80^{2} \\
& =16,741 \mathrm{KN} / \mathrm{m} \\
\Sigma \mathrm{Pp} & =16,741 \mathrm{KN} / \mathrm{m}
\end{aligned}
$$

a. Jarak $\mathrm{Y}$ terhadap titik A

$$
\begin{aligned}
\text { Ya1 } & =1 / 3(\mathrm{H} 1+\mathrm{H} 2) \\
& =1 / 3(5,20+0,80) \\
& =2 \mathrm{~m} \\
\text { Ya2 } & =1 / 2(\mathrm{H} 1+\mathrm{H} 2) \\
& =1 / 2(5,20+0,80) \\
& =3 \mathrm{~m} \\
\text { Yp } & =1 / 3(\mathrm{H} 2) \\
& =1 / 3(0,80) \\
& =0,267 \mathrm{~m} \\
\text { Yair } & =1 / 3(\mathrm{H}-\mathrm{Z}) \\
& =1 / 3(6-1,6) \\
& =1,47 \mathrm{~m}
\end{aligned}
$$


Perhitungan Stabilitas

a. Faktor keamanan terhadap guling (Overturning)

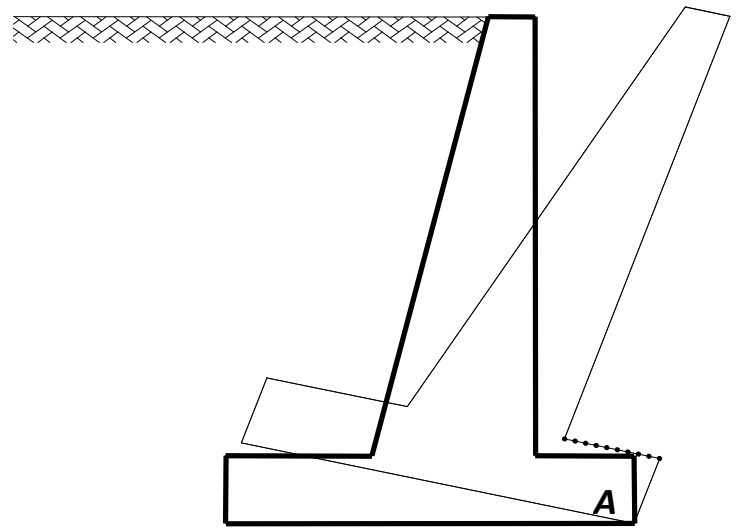

$\mathrm{Ph}$

$=\mathrm{Pa}$

$=121,957$

$\mathrm{KN} / \mathrm{m}$

) $\mathrm{KN} / \mathrm{m}$

$=\operatorname{Ph}\left(\frac{H}{3}\right)$

$=121,957$

$\mathrm{KN} / \mathrm{m}$

$$
\begin{array}{ll}
\text { FSguling } \quad= & \frac{\Sigma M R}{\Sigma M 0} \\
= & \frac{794,589}{243,915} \\
= & 3,258 \geq 2
\end{array}
$$

b. Faktor keamanan terhadap geser (Sliding)

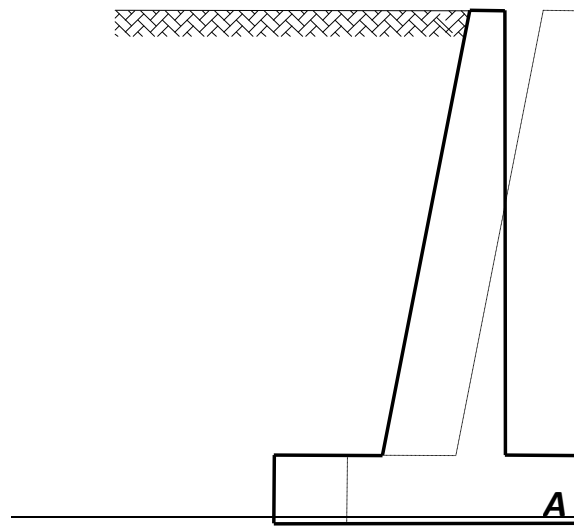

ISSN 2599-2081

A $A$

Fakultas Teknik UMSB

$$
\begin{aligned}
\text { FSgeser } & =\frac{(\Sigma V) \tan \left(\frac{2}{3} \emptyset\right)+\left(B \frac{2}{3} c\right)+P p+P \text { air }}{P h} \\
& =\frac{(334,700 * 0,383)+10,400+16,741+96,800}{121,957} \\
& =2,067 \geq 1,5
\end{aligned}
$$

Berdasarkan tabel daya dukung, untuk $\varnothing$ $31,50^{\circ}$, dari tabel diperoleh :

$\mathrm{Nc}=34,08$

$\mathrm{Nq}=21,91$

$\mathrm{N} \gamma=28,11$

Maka :

$q u=(c \times N c \times$ Fcd $\times$ Fci $)+(q \times N q \times F q d x$

Fqi) $+\left(0,5 \times \gamma \times B^{\prime} \times \mathrm{N} \gamma \times \mathrm{F} \gamma \mathrm{d} \times \mathrm{F} \gamma \mathrm{i}\right)$

$$
=(4 * 34,08 * 1,10 * 0,608)+
$$

$(13,12 * 21,91 * 1,07 * 0,608)+$

$$
\begin{aligned}
& (0,5 * 16,4 * 3,30 * 28,11 * 1 * 0,138) \\
= & 91,003+186,758+104,621 \\
= & 382,381 \mathrm{KN} / \mathrm{m}^{2 \backslash}
\end{aligned}
$$

$$
\frac{5,20+0,80}{3}
$$

$F S_{\text {dayradukung }}=\frac{q u}{q \max }=\frac{382,381}{126,053}=3,033 \geq$ $3 \ldots \ldots \ldots o k$

\section{SIMPULAN \\ Simpulan}

Berdasarkan hasil dan pembahasan maka dapat diambil beberapa kesimpulan dari penulisan adalah sebagai berikut :

1. Perencanaan struktur dinding penahan tanah ini direncanakan aman terhadap pergeseran, penggulingan, dan keruntuhan kapasitas daya dukung tanah. Hasil analisis faktor stabilitas 
terhadap geser 2,067 >1,5 (aman), stabilitas terhadap guling $3,258>2$ (aman), keruntuhan kapasitas daya dukung 3,033 $>3$ (aman)

2. Cara perbaikan tebing sungai akibat hantaman banjir ataupun oleh gerusan air dapat dilakukan dengan membuat dinding penahan dengan tipe dinding penahan gravitasi, dinding penahan kantilever, dinding penahan beton bertulang dengan dinding penyokong dan dinding penahan concrete sheet pile (tiang pancang beton).

\section{DAFTAR PUSTAKA}

Bambang Surendro. (2014). Mekanika Tanah.

Penerbit Andi. Yogyakarta

Hardiyatmo, H.C. (2010). Mekanika Tanah I.

Penerbit Gadjah mada University Press, Yogyakarta.

Hardiyatmo, H.C. (2011). Mekanika Tanah II.

Penerbit Gadjah mada University Press, Yogyakarta.

Gunawan, T. Margaret ,S (2006). Mekanika Tanah Soal dan Penyelesaian. Delta Teknik. Jakarta.

Suwardi (2009). Jurnal Teknik Sipil vol.7 No.2, Surakarta 